\title{
Review evolution of cellular manufacturing system's approaches: Human resource planning method
}

\author{
Aidin Delgoshaei ${ }^{{ }^{*}}$, Armin Delgoshaei ${ }^{\mathrm{b}}$ and Ahad Ali \\ ${ }^{a}$ Department of Industrial Engineering, University of Kharazmi, Tehran, Iran \\ ${ }^{b}$ Department of Industrial Engineering, Khaje Nasir Toosi University of Technology, Tehran, Iran \\ ${ }^{c}$ Lawrence Technological University, United States \\ CHRON I C L E \\ Article history: \\ Received: June 102018 \\ Received in revised format: July 1 \\ 2018 \\ Accepted: July 252018 \\ Available online: \\ July 252018 \\ Keywords: \\ Human resource management

\begin{abstract}
A B S T R A C T a review of 43 dominant research papers available in the literature. The advantages, limitations, and drawbacks of material transferring methods have been discussed as well. The domains of the examined studies include some of the important problems in staff planning, such as worker assigning, hiring and firing, optimum number of workers, skilled workers, cross-functional exclarify many related questions in CMS problems.
\end{abstract} \\ This paper presents a review of human resource planning methods, related techniques, and their \\ effects on cellular manufacturing systems (CMS). In-depth analysis has been conducted through \\ perts, worker satisfaction and outsourcing. The results of this study can fill research gaps and
}

Cellular Manufacturing systems

Staff planning
(C) 2019 by the authors; licensee Growing Science, Canada.

\section{Introduction}

Facility design is a significant requirement in manufacturing systems engineering. Tompkins et al. (2003) reported that an estimated sum of over $\$ 250$ billion has been spent annually in the US for facility designing, planning, and re-planning. Around $20 \%$ to $50 \%$ of the total cost of manufacturing systems is spent on material handling. The same source reported that effective planning can reduce such costs by over $10 \%$ to $30 \%$. Group technology can be defined as an engineering philosophy of recognizing similar parts and grouping them together to take advantage of similar product designing and manufacturing. Using an effective production scheduling that is supported by an appropriate cell design can result in a significant amount of savings in the total cost of systems, including setup, operation, material transferring, and maintenance costs. The cellular manufacturing system (CMS) is considered an effective way of using group technology; the manufacturing process is defined as a hybrid system of cells using the advantages of both jobbing (flexibility) and mass (efficient flow and high production rate) production approaches (Fig. 1) (Papaioannou \& Wilson, 2010). During the year 2013, U.S spent \$7.0 billion for trainings and employments. So, human resource management (HRM) is considered as an important issue should not be ignored during CMS study. Through last 3 decades, scientists did their best to define and solve HRM problems in different circumstances, conditions and situations to find out new ways to reduce such expenses. In continue the most important and related problems of human resource planning in CMS will be explained.

* Corresponding author.

E-mail address: delgoshaei.aidin@gmail.com (A. Delgoshaei) 


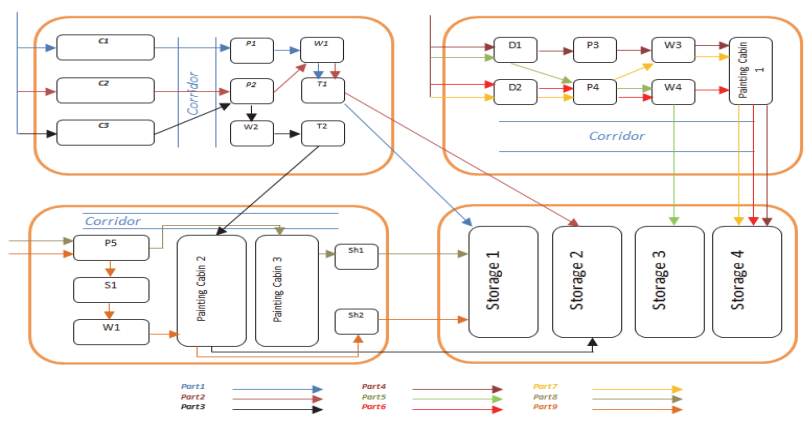

Fig. 1. A Flow Diagram of worker assignment in a Cellular Manufacturing System

\subsection{Optimum Number of Workers}

Perhaps, finding the optimal number of workers is the main idea of investigating HRM in CMS. To determine optimal number of operators and part assignment, Park and Lee (1995) developed a 2-stage model while in first stage, a Taguchi method was used to determine system performance which was then used as objective function of assigning model. The idea of maximizing saving costs between operation and outsourcing costs was investigated by Heady (1997). But their model did not investigate operator level, training, hiring and firing costs. Norman et al. (2002) proposed a model to assign workers in manufacturing cells in order to maximize the system profit. Ertay and Ruan (2005) developed the idea of determining number of operators for maximizing number of outputs. For this purpose, using weighted input data, a data envelopment analysis (DEA) was applied. But in the proposed model, the same skill for all operators and machines was considered.

\subsection{Promoting and Assigning Skilled Workers}

Since in real industries, operator's skill are not same, so their outputs will not be the same. The idea of considering operator levels was investigated by Suer and Cedeño (1996). For this purpose, a mixed integer programming method was used to generate alternative operator levels and then another integer programming is employed to find the optimal operator assignments to the cells. Askin and Huang (1997) used integer programming for assigning workers to cells in order to determine a training program for employees. Aryanezhad et al. (2009) considered 3 skill levels for workers, which can be promoted through the planning horizon by training. Then a multi-period scheduling model was developed for simultaneous cell forming and worker assignning. Jannes et al. (2005) focused on assiginings workers to team works with the aims of minimizing training and assigning costs as well as maximizing labor flexibility. In the same year, Fitzpatrick and Askin (2005) argued that elemens of a good team formation is not limited to personnal skills and characteristics but technological and human interactions. Hence, by using pre-determined skill level measures, they tried to select workers and assign them to appropriate teams in cells to maximize team performance. Cesaní and Steudel (2005)

focused on some factors on deployment of labors. Then, they focused on work sharing, work balancing and leveling the operator assignments (in presence of bottleneck operations). To prevent overloading and over-assigning of operators, Satoglu and Suresh (2009) used goal programming in a mathematical model where the objectives were minimizing over assignment of workers, cross training, hiring and firing costs.

\subsection{Cross-trained workers}

Note that cross-trained workers are refered to those workers that are trained to perofrm more than one task. Determinining best sets of crosstraining workers can improve system performance with more flexibility. Bartholdi and Eisenstein (1996) found that by using large work cells with multiple workstations and workers, a stable partition and assignment of work will spontaneously emerge that cause balance production lines and maximize the production rate. Kleiner et al. (1998) assumed a typical skilled workers, which can perform multi tasks with multifunctional machines, in a computer based system. Other attributes of the proposed model were included cell lead time, part travel distance, 
process yield, operator classification and labor efficiency. In continue, Gel et al. (2000) showed that cross-trained workers can achieve higher performance than normal workers. As a different point of view, Askin and Huang (2001) studied the performance of greedy, beam search, and simulated annealing for a multi-objective optimization model for the formation of worker teams and a cross-training plan for cellular manufacturing. Olorunniwo and Udo (2002) showed that top management role and employee cross-trained have significant impact on the successful implementation of CMS. Kher (2000b) focused on training schemes that obtained by using cross-trained workers under learning, relearning, and attrition conditions. The idea of distributing skilled workers within teams and the degree of workforce belongs to Molleman and Slomp (1999) where they indicated the mentioned items have significant impact on system performance. Their findings showed that a uniform distribution of workforce skill resulted better system performance and consequently each worker should master the same number of tasks. Later, Slomp and Molleman (2000) compared four cross-training policies based on the workload of the bottleneck worker in both static and dynamic circumstances. The results confirmed that better team performance can be expected by using higher levels of cross-training workers. Jensen (2000) involved with staffing level and shop layouts in departmental, strictly and hybrid cell layouts. By changing number of employees in each department and considering 3 levels of workload balance and 2 labor transferring rules, they evaluated flow time, mean of tardiness and square mean of job tardiness. Li et al. (2012) focused on minimizing average salary while maximizing average of satisfaction. For this purpose they developed a multi-objective mixed integer programming to determine number of cross-trained labors and also tasks that must be assigned to the labors in flexible assembly cell layout. Another contribution of their research was considering worker's satisfaction and task redundancy levels.

\subsection{Dual Resource Problems}

Dual constraint resource problems refers the problems where scheduling parts on machines and workers simultaneously. Kher (2000a) has investigated training schemes obtained by cross-trained workers under learning, relearning, and attrition conditions. Kher et al. (1999) further conclude that the effectiveness of cross-training depends significantly on the existing forgetting rate of the workers. In addition, they remarked on the significant relationship between batch size and worker flexibility cross-training include variability, labor interaction, resources utilization and transition efficiency. Molleman \& Slomp (1999)indicate that the distribution of skill within teams and the degree of workforce multi-functionality have a significant impact on system performance. Their findings indicate that a uniform workforce skill distribution resulted in better system performance. In other words, each worker should master the same number of tasks. Xu et al. (2011) provided a novel research in dual resource systems. Hamedi et al. (2012) developed a model where parts, machines and workers are grouped and assigned to the generated virtual cells simultaneously. In continue, the developed model is solved through a multi-objective Tabu Search algorithm to find near optimum solutions.

\subsection{Uncertain Market Demands}

The idea considering dynamic part demands in HRM-CMS which can cause system imbalance is less developed. To solve this problem, Mahdavi et al. (2010) developed an a multi-mode planning model for assigning workers to cells in a reconfigurable CMS. In the proposed model, hiring, firing and also salary costs were considered as a part of total system costs. Another contribution of their model was considering available time for workers. As described in pervious section, Mahdavi et al. (2012) focused on inter-cellular movements of workers and parts while processing on specific machine. Min and Shin (1993) considered the skilled human resource as a part of cell forming process. Their objective was finding machine operators with similar expertise and skills to produce similar part families. Black and Schroer (1993) investigated a case where multi-functional operators can walk within cells to complete operations. They reported that using portable work stations can increase the output rate. Morris and Tersine (1994) examined the impact of labor and equipment in a dual constraint resource planning to compare the process layouts and cell layouts. Hyer et al. (1999) carried out a filed study considering 8 human factors in cell systems to find the importance of different human factors may influence the CMS. As a result they concluded that communication and tem work ranked as the most important factors in 
utilizing the cell systems.Cesaní and Steudel (2005) developed a 2 phase frame work for worker assignment in CMS based on human resource factors. In the first phase, they performed an empirical investigation to find important factors that affect the labor flexibility. In second phase they used these factors to find optimum worker assignment in cells. The contribution of their research is finding balance between the operators' workload, the level and type of machine sharing to increase the performance of cell based systems. Chakravorty and Hales (2004) provided a case study to survey the impact of worker assignment on system performance in a manufacturer and supplier of residential and light commercial building products. Afterward, Chakravorty and Hales (2008) reported that during early stage of working after forming cells, both technical failures and human resource errors are existed. However, after spending a period although the technical problems may reduce but the human resource problems are still exists which must be managed to reduce the harms. Yu et al. (2014) focused on minimizing total labor hour while maximizing throughput time of products in a line-cell conversion problem. They found that implementing the proposed method can increase the workforce motivation. Jannes Slomp et al. (2005) proposed a new method which considered labor grouping as well as machine part grouping during the cell forming process. The contribution of their research is focusing on balanced loads for workers, minimization of inter-cell movements of workers, providing adequate levels of labor flexibility. Saidi-Mehrabad et al. (2013) considered training workers as a part of a multi-period planning model to increase the throughput of the system while the available time of each worker is restricted. In their model they clustered the workers according to their work skill levels. McDonald et al. (2009) focused on worker assigning into cells in order to minimize the net present cost while cross-trained workers are taken into consideration. Yu et al. (2013) offered a solution to reduce number of workers without affecting on system performance. Their method emphasizes on determining the number of cells during cell forming step and assigning appropriate skilled workers to cells. Mosier and Mahmoodi (2002) focused on different labor scheduling policies in CMS problem where labor utilization was measured by setups, tear-downs and loads. They found that using simple scheduling methods provides better results than complicated ones. Süer et al. (2008) focused on minimizing total number of tardy jobs and optimizing the number of workers concurrently. For this purpose, 4 mathematical models were developed considering varied system and operation circumstances. Zhang et al. (2008) focused on human task spectrum, human error and occupational requirements in process of shifting from conventional cell system to autonomous production cells.

\section{Comparison of Methods}

To provide a comprehensive analysis of the methods that were developed to minimize human resource planning costs, a comparison of the reviewed studies is needed. The purpose is to determine the contributions, advantages, and drawbacks of different methods and approaches. Table 1 and table 2 analyze the examined studies according to their methods and objectives of each research. Table 3 provides a list of the investigated problems and suggested solutions. Table 4 provides a list of the objective functions that are frequently used in research, and table 5 explains the constraints that are commonly considered by scientists. Table 6 and table 7 analyze the contributions and significant points of each method. Table 8 shows the databases and the references commonly used by scientists; the information can be helpful in providing bases to check the validity or performance of the proposed methods and algorithms in future studies.

\section{Analytical Comparison}

The review of the selected studies shows that in $75.3 \%$ of the investigated cases, worker assignment is the main objective, whereas in other studies, the benefits of maximizing skill level and labor efficiency were reported as the focus. Around $21.2 \%$ of the cases considered hiring and firing, whereas $56.5 \%$ considered outsourcing. Only $18.8 \%$ of the studied cases investigated worker satisfaction. The quota of the cases focused on dynamic circumstances was less than $22.3 \%$, whereas others performed in exact conditions. Despite fuzzy method abilities, less than $7.1 \%$ of the examined studies used fuzzy concepts to solve the problems involved. 


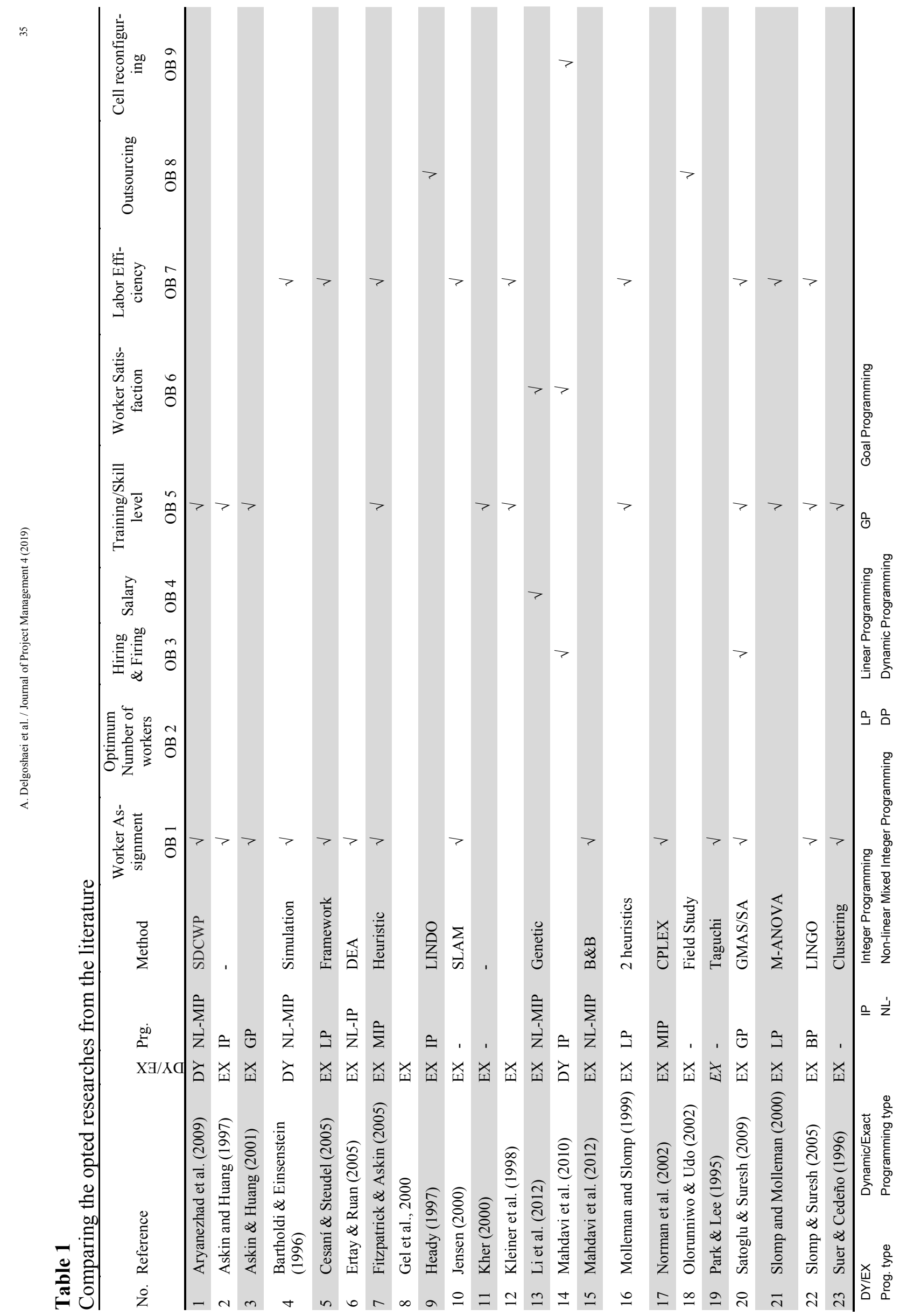




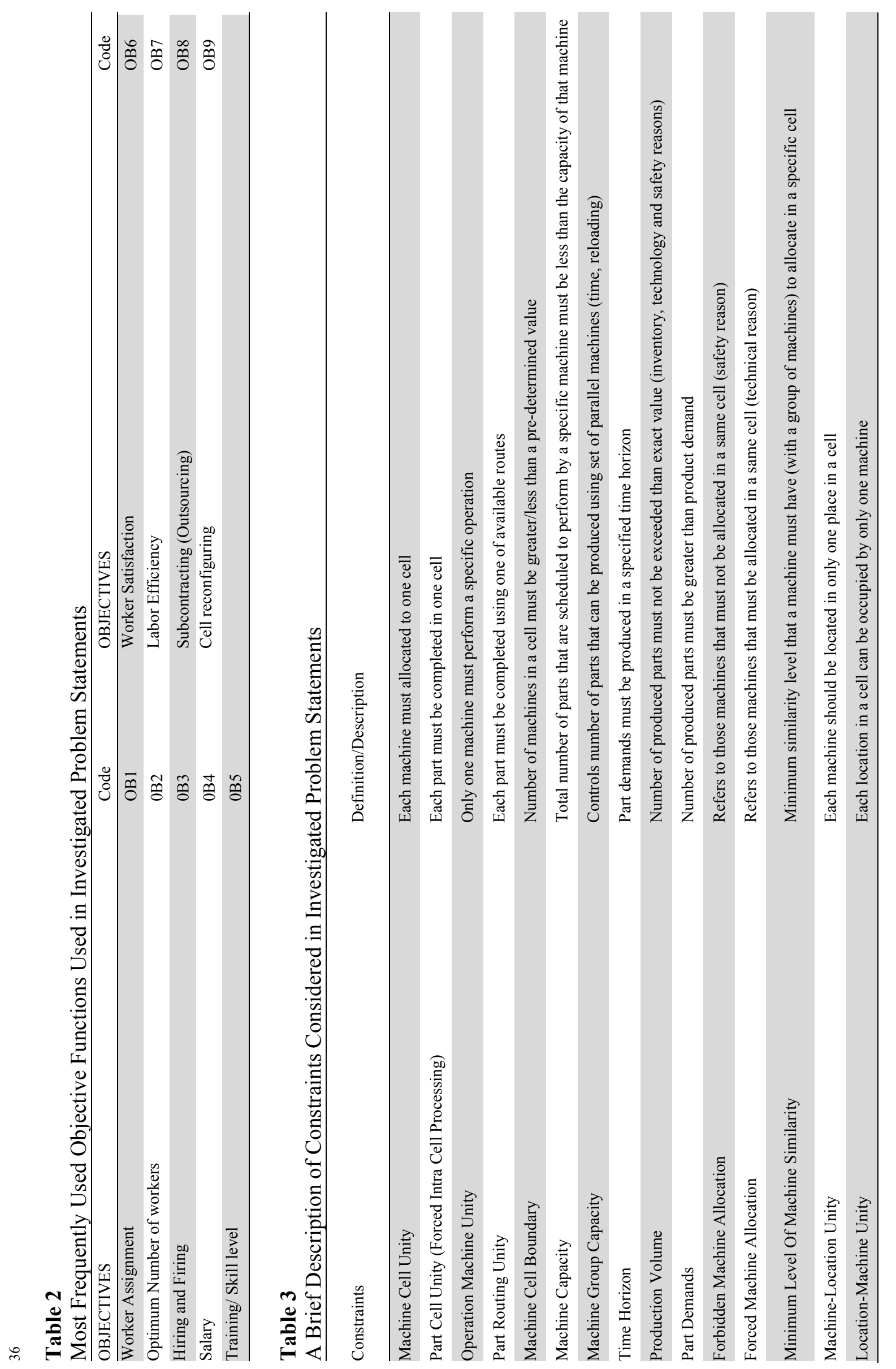




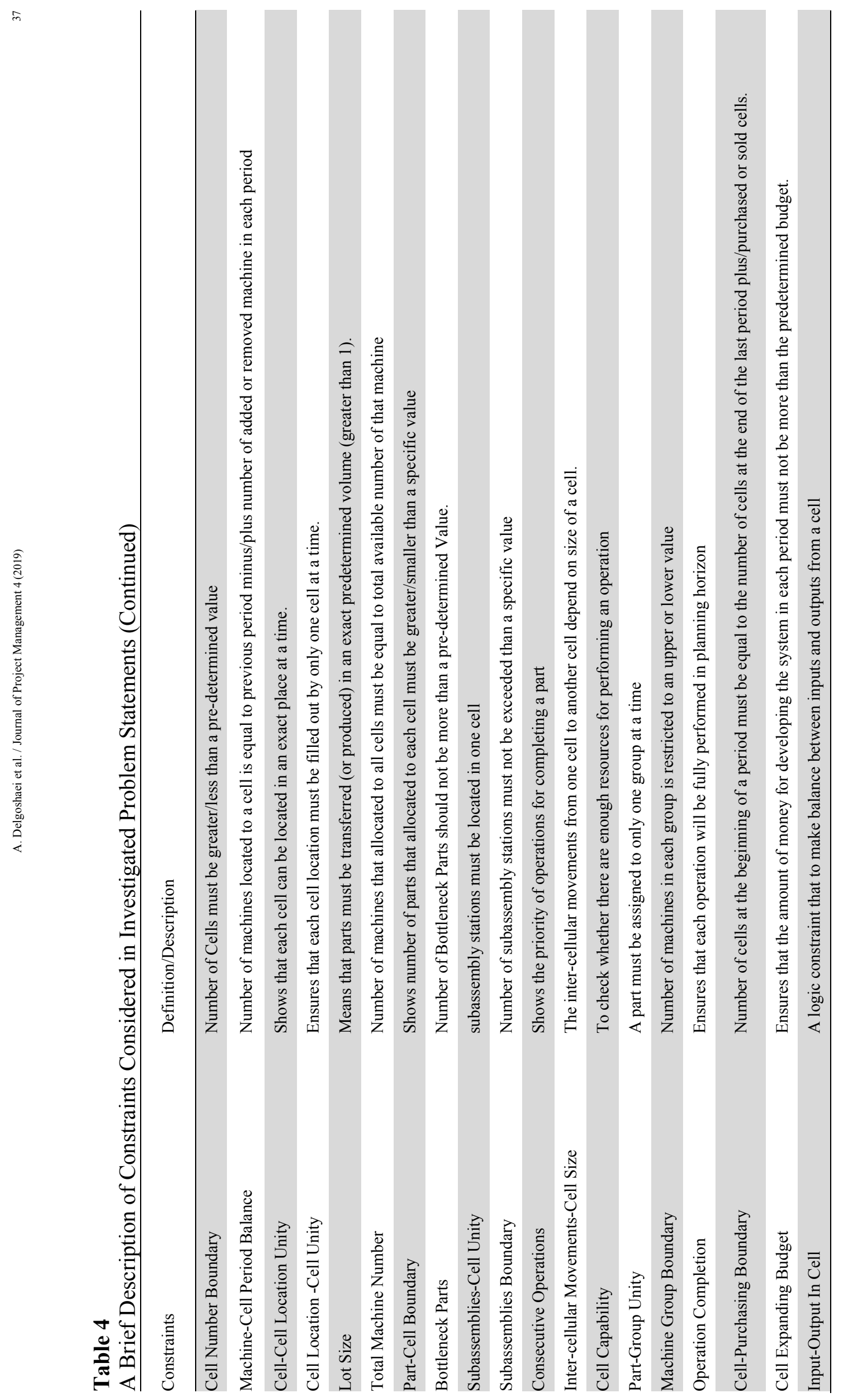




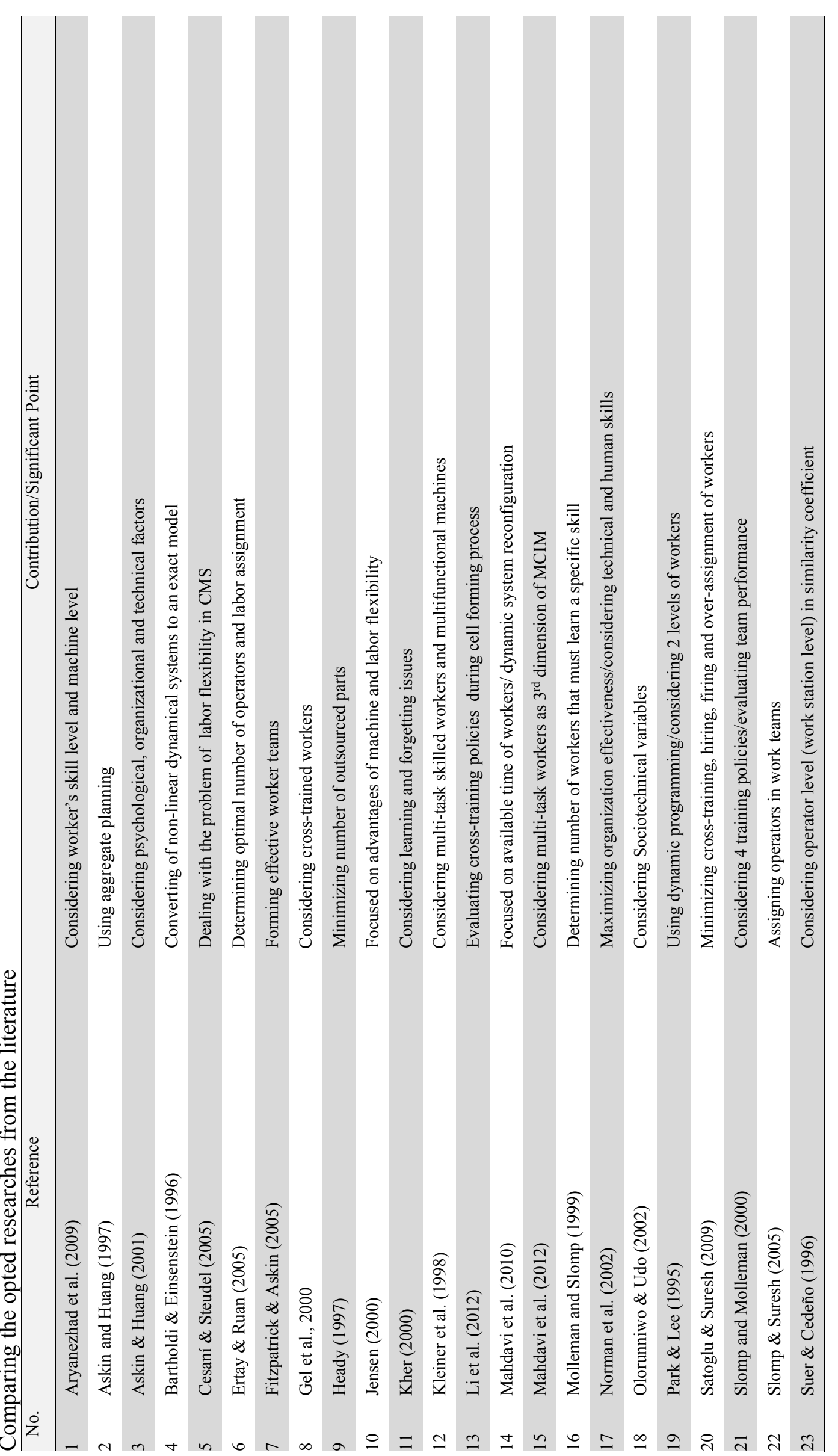




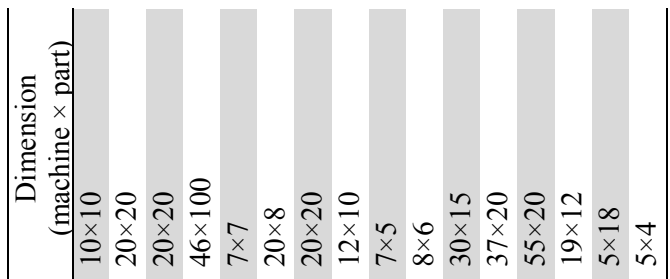

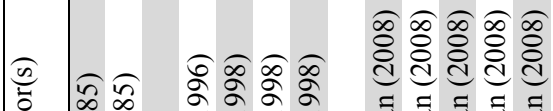

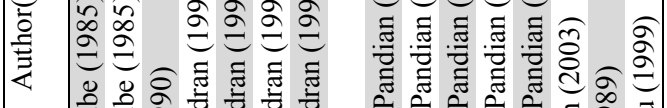

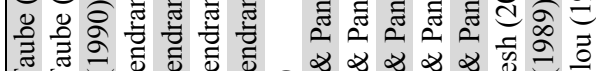

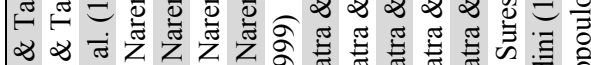

.

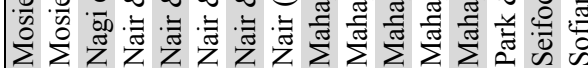$$
\text { क्ष }
$$

紫

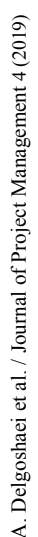

苟

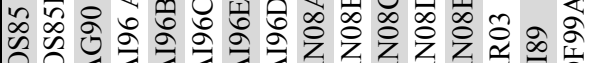

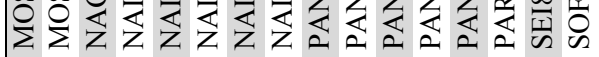

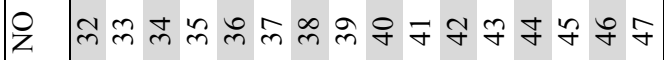

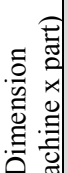

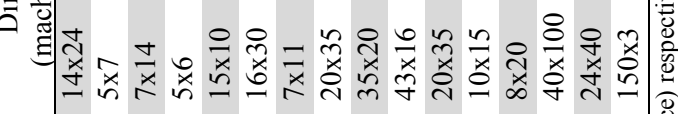

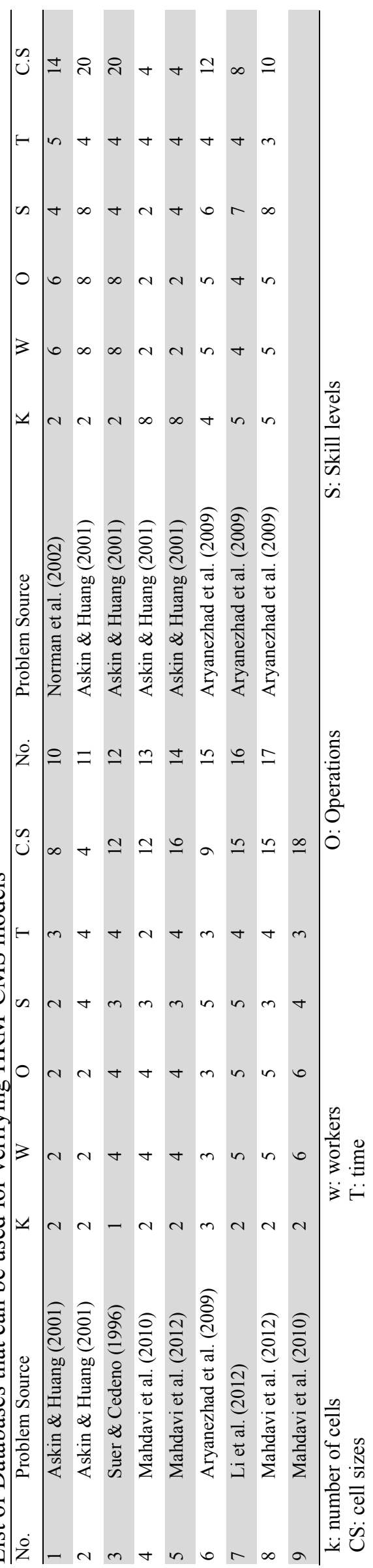




\section{Conclusions}

This paper presented a review of the issues on staff planning during the scheduling process in CMS. The most significant drawbacks that emerge through scheduling are illustrated, and the proposed solutions in various situations are investigated. The literature review shows that when the part routing issue emerges, considering multi process plans, machine relocating, cell decomposition, and cell reconfiguring are the most common solutions offered by scientists. However, some gaps are also found in this area. To the best of our knowledge, no efficient method exists to find trading off between human resource management (part allocation, hiring, firing and training) and outsourcing while part demands and system costs are considered uncertain. In addition, no record is available to evaluate the effect of using uncertain part demands in CMS while cross training staff are available. No records also exist to evaluate the effects of uncertain costs in human allocation problems. Moreover, the time value of money can be considered as a major gap in multi-horizon planning models.

The existence of exceptional elements and voids can also increase human resource relocating costs and cell load variation accordingly. Reconfiguring cells is the most common strategy to eliminate the voids that affect human resource locating/allocating costs. The other successful solutions in this area are cell decomposing and cell relocating. The existence of bottleneck products is sometimes unavoidable, but in many cases, an efficient human resource allocating can smooth the expected costs through planning horizons. While uncertain part demands need to be considered, the use of outsourced services and cell reconfiguring are successfully employed. To the best of our knowledge, the problem on finding tradeoff values between in-house manufacturing and outsourcing with backorder and lost sale conditions considered has yet to be fully developed.

The following are the conclusions based on the statistical results. Developing multiple step methods results in more robust solutions than using a single one. To the best knowledge of the authors, the use of fuzzy methods to minimize staff planning costs is less developed. In addition, only a few studies used fuzzy terms while scheduling CMS. Only $21 \%$ of the studies examined considered time factor in their proposed models (multi-period scheduling), whereas the rest did not consider such factor.

\section{Acknowledgements}

The authors would like to thank the editors and anonymous reviewers for their constructive comments which served to improve the manuscript.

\section{References}

Aryanezhad, M., Deljoo, V., \& Mirzapour Al-e-hashem, S. (2009). Dynamic cell formation and the worker assignment problem: a new model. The International Journal of Advanced Manufacturing Technology, 41(3-4), 329-342.

Askin, R., \& Huang, Y. (1997). Employee training and assignment for facility reconfiguration. Proceedings of the sixth IERC, Miami, FL, 426-431.

Askin, R., \& Huang, Y. (2001). Forming effective worker teams for cellular manufacturing. International Journal of Production Research, 39(11), 2431-2451.

Bartholdi, J. J., \& Eisenstein, D. D. (1996). A production line that balances itself. Operations Research, 44(1), 21-34.

Black, J., \& Schroer, B. J. (1993). Simulation of an apparel assembly cell with walking workers and decouplers. Journal of Manufacturing Systems, 12(2), 170-180.

Cesaní, V. I., \& Steudel, H. J. (2005). A study of labor assignment flexibility in cellular manufacturing systems. Computers \& industrial engineering, 48(3), 571-591.

Chakravorty, S. S., \& Hales, D. N. (2004). Implications of cell design implementation: A case study and analysis. European Journal of Operational Research, 152(3), 602-614. 
Chakravorty, S. S., \& Hales, D. N. (2008). The evolution of manufacturing cells: An action research study. European Journal of Operational Research, 188(1), 153-168.

Ertay, T., \& Ruan, D. (2005). Data envelopment analysis based decision model for optimal operator allocation in CMS. European Journal of Operational Research, 164(3), 800-810.

Fitzpatrick, E. L., \& Askin, R. G. (2005). Forming effective worker teams with multi-functional skill requirements. Computers \& industrial engineering, 48(3), 593-608.

Gel, E., Hopp, W., \& Van Oyen, M. (2000). Workforce agility in systems with hierarchical crosstraining. Retrieved from

Hamedi, M., Esmaeilian, G., Ismail, N., \& Ariffin, M. (2012). Capability-based virtual cellular manufacturing systems formation in dual-resource constrained settings using Tabu Search. Computers \& Industrial Engineering, 62(4), 953-971.

Heady, R. B. (1997). Forming minimum-cost machine cells with exceptional parts using zero-one integer programming. Journal of Manufacturing Systems, 16(2), 79-90.

Hyer, N. L., Brown, K. A., \& Zimmerman, S. (1999). A socio-technical systems approach to cell design: case study and analysis. Journal of Operations Management, 17(2), 179-203.

Jensen, J. B. (2000). The impact of resource flexibility and staffing decisions on cellular and departmental shop performance. European Journal of Operational Research, 127(2), 279-296.

Kher, H. V. (2000a). Examination of flexibility acquisition policies in dual resource constrained job shops with simultaneous worker learning and forgetting effects. Journal of the Operational Research Society, 51(5), 592-601.

Kher, H. V. (2000b). Examination of flexibility acquisition policies in dual resource constrained job shops with simultaneous worker learning and forgetting effects. Journal of the Operational Research Society, 592-601.

Kher, H. V., Malhotra, M. K., Philipoom, P. R., \& Fry, T. D. (1999). Modeling simultaneous worker learning and forgetting in dual resource constrained systems. European Journal of Operational Research, 115(1), 158-172.

Kleiner, B. M., Drury, C. G., \& Palepu, P. (1998). A computer-based productivity and quality management system for cellular manufacturing. Computers \& industrial engineering, 34(1), 207217.

Li, Q., Gong, J., Fung, R. Y., \& Tang, J. (2012). Multi-objective optimal cross-training configuration models for an assembly cell using non-dominated sorting genetic algorithm-II. International Journal of Computer Integrated Manufacturing, 25(11), 981-995.

Mahdavi, I., Aalaei, A., Paydar, M. M., \& Solimanpur, M. (2010). Designing a mathematical model for dynamic cellular manufacturing systems considering production planning and worker assignment. Computers \& Mathematics with Applications, 60(4), 1014-1025.

Mahdavi, I., Aalaei, A., Paydar, M. M., \& Solimanpur, M. (2012). A new mathematical model for integrating all incidence matrices in multi-dimensional cellular manufacturing system. Journal of Manufacturing Systems, 31(2), 214-223.

McDonald, T., Ellis, K. P., Van Aken, E. M., \& Patrick Koelling, C. (2009). Development and application of a worker assignment model to evaluate a lean manufacturing cell. International Journal of Production Research, 47(9), 2427-2447.

Min, H., \& Shin, D. (1993). Simultaneous formation of machine and human cells in group technology: a multiple objective approach. THE INTERNATIONAL JOURNAL OF PRODUCTION RESEARCH, 31(10), 2307-2318.

Molleman, E., \& Slomp, J. (1999). Functional flexibility and team performance. International Journal of Production Research, 37(8), 1837-1858.

Morris, J. S., \& Tersine, R. J. (1994). A simulation comparison of process and cellular layouts in a dual resource constrained environment. Computers \& industrial engineering, 26(4), 733-741.

Mosier, C. T., \& Mahmoodi, F. (2002). Work sequencing in a manufacturing cell with limited labour constraints. International Journal of Production Research, 40(12), 2883-2899. 
Norman, B. A., Tharmmaphornphilas, W., Needy, K. L., Bidanda, B., \& Warner, R. C. (2002). Worker assignment in cellular manufacturing considering technical and human skills. International Journal of Production Research, 40(6), 1479-1492.

Olorunniwo, F., \& Udo, G. (2002). The impact of management and employees on cellular manufacturing implementation. International Journal of Production Economics, 76(1), 27-38.

Papaioannou, G., \& Wilson, J. M. (2010). The evolution of cell formation problem methodologies based on recent studies (1997-2008): Review and directions for future research. European Journal of Operational Research, 206(3), 509-521.

Park, T., \& Lee, H. (1995). Design of a manufacturing cell in consideration of multiple objective performance measures. Manufacturing research and technology, 24, 181-202.

Saidi-Mehrabad, M., Paydar, M. M., \& Aalaei, A. (2013). Production planning and worker training in dynamic manufacturing systems. Journal of Manufacturing Systems, 32(2), 308-314.

Satoglu, S. I., \& Suresh, N. C. (2009). A goal-programming approach for design of hybrid cellular manufacturing systems in dual resource constrained environments. Computers \& industrial engineering, 56(2), 560-575.

Slomp, J., Chowdary, B. V., \& Suresh, N. C. (2005). Design of virtual manufacturing cells: a mathematical programming approach. Robotics and Computer-Integrated Manufacturing, 21(3), 273-288.

Slomp, J., \& Molleman, E. (2000). Cross-training policies and performance of teams. Paper presented at the Group technology/cellular manufacturing world symposium.

Slomp, J., \& Suresh, N. C. (2005). The shift team formation problem in multi-shift manufacturing operations. European Journal of Operational Research, 165(3), 708-728.

Süer, G. A., Arikan, F., \& Babayiğit, C. (2008). Bi-objective cell loading problem with non-zero setup times with fuzzy aspiration levels in labour intensive manufacturing cells. International Journal of Production Research, 46(2), 371-404.

Suer, G. A., \& Cedeño, A. A. (1996). A configuration-based clustering algorithm for family formation. Computers \& industrial engineering, 31(1), 147-150.

Tompkins, J., White, J., Bozer, Y., \& Tanchoco, J. (2003). Facilities planning. 2003: Wiley, New York.

Xu, J., Xu, X., \& Xie, S. (2011). Recent developments in Dual Resource Constrained (DRC) system research. European Journal of Operational Research, 215(2), 309-318.

Yu, Y., Tang, J., Gong, J., Yin, Y., \& Kaku, I. (2014). Mathematical analysis and solutions for multiobjective line-cell conversion problem. European Journal of Operational Research, 236(2), 774786.

Yu, Y., Tang, J., Sun, W., Yin, Y., \& Kaku, I. (2013). Reducing worker (s) by converting assembly line into a pure cell system. International Journal of Production Economics, 145(2), 799-806.

Zhang, X., Schmidt, L., Schlick, C., Reuth, R., \& Luczak, H. (2008). A human task-oriented simulation study in autonomous production cells. International Journal of Production Research, 46(18), 50135041.

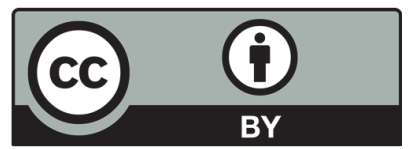

(C) 2018 by the authors; licensee Growing Science, Canada. This is an open access article distributed under the terms and conditions of the Creative Commons Attribution (CC-BY) license (http://creativecommons.org/licenses/by/4.0/). 